\title{
Actividad Letal in vitro del Extracto Proteico Total de Bacillus thuringiensis sobre Huevos y Larvas (L3) Infectivas de Nematodirus Spathiger
}

\author{
In vitro Lethal Activity of Extract Protein Bacillus thuringiensis against \\ Nematodirus spathiger EgGS AND INFECTIVE LARVAE (L3)
}

Adolfo Alfredo Ochoa Silvera ${ }^{1,3}$, Fidel Rodolfo Mujica Lengua ${ }^{2}$

\section{Resumen}

\begin{abstract}
Se obtuvo una suspensión conteniendo el extracto proteico total de Bacillus thuringiensis de las variedades kurstaki HD-1, thompsoni HD-542, neoleonensis T-24001, israeliensis HD-500 e israeliensis WHO-2013-9 y se determinó la concentración $(\mathrm{mg} / \mathrm{ml})$ de cada variedad por el método de Biuret. La actividad nematicida se evaluó en placas de Petri enfrentando huevos y larvas (L3) infectivas de Nematodirus spathiger contra la suspensión del extracto proteico total $(1.2 \mathrm{ml})$, considerando cinco tratamientos (variedades) y 10 repeticiones. El grupo control solo contenía nematodos. Las placas de Petri se incubaron a $25^{\circ} \mathrm{C}$ por 24,48 y $72 \mathrm{~h}$. La variedad kurstaki HD- 1 en una concentración de $5.042 \mathrm{mg} / \mathrm{ml}$ fue la variedad con mayor eficiencia antihelmíntica en los tres tiempos de incubación, obteniendo una mortalidad de $44.7 \%$ en huevos y $45.6 \%$ en larvas. El extracto proteico total de $B$. thuringiensis variedad kurstaki HD-1 contiene las toxinas nematicidas que pudieran ser empleadas para el futuro en pruebas in vivo con animales infectados experimentalmente con $N$. spathiger.
\end{abstract}

Palabras clave: Bacillus thuringiensis, Nematodirus spathiger, control biológico

\section{Abstract}

A suspension containing the total protein extract of Bacillus thuringiensis of five strains (kurstaki HD-1, thompsoni HD-542, neoleonensis T-24-001, israeliensis HD-500 and israeliensis WHO-2013-9) was obtained. The concentration ( $\mathrm{mg} / \mathrm{ml}$ ) of each strain was determined by the Biuret method. The nematicidal activity was evaluated in Petri plates facing eggs and infective larvae (L3) of Nematodirus spathiger against the

\footnotetext{
${ }^{1}$ Laboratorio de Parasitología Veterinaria, Escuela de Formación Profesional de Medicina Veterinaria, ${ }^{2}$ Laboratorio de Biotecnología, Escuela de Formación Profesional de Biología, Universidad Nacional de San Cristóbal de Huamanga, Ayacucho, Perú

${ }^{3}$ E-mail: aaos_20@hotmail.com
}

Recibido: 11 de diciembre de 2014

Aceptado para publicación: 20 de abril de 2015 
suspension of total protein extract $(1.2 \mathrm{ml})$. Five treatments (strains) and 10 repetitions were used. The control group contained only the nematodes. The Petri dishes were incubated at $25{ }^{\circ} \mathrm{C}$ for 24,48 and 72 h. Kurstaki HD-1 strain in a concentration of 5.042 $\mathrm{mg} / \mathrm{ml}$ showed the best anthelmintic efficiency in the three incubation times, obtaining $44.7 \%$ mortality in eggs and $45.6 \%$ in larva. The total protein extract of B. thuringiensis kurstaki HD-1 contains the nematicidal toxins that could be used for future in vivo experimentally infected animals with $N$. spathiger.

Key words: Bacillus thuringiensis, Nematodirus spathiger, biological control

\section{INTRODUCCIÓN}

La ganadería en los Andes peruanos constituye una importante fuente de ingresos económicos a la población rural; sin embargo, el parasitismo gastrointestinal afecta el rendimiento productivo de los animales, disminuyendo la producción lechera, cárnica y de lana, siendo su tratamiento costoso y, en algunas ocasiones, ineficaz.

De los nematodos gastrointestinales en estado adulto hallados en el tracto gastrointestinal de ovinos, la especie Nematodirus spathiger se encuentra presente en el $55.1 \%$ de los casos, frente a otros nematodos como Bunostomum trigonocephalum (24.8\%), Trichuris ovis (12.7\%), Chabertia ovina (5.9\%) y Oesophagostomun venulosum (1\%) (Gómez, 1984). $N$. spathiger se le encuentra tanto en el periodo lluvioso como en el seco, principalmente debido a que la larva infectiva se desarrolla dentro del huevo, lo cual le confiere una mayor resistencia a los factores adversos del medio ambiente. Además su eclosión es favorecida por estímulos térmicos (enfriamiento y calentamiento) existentes en las regiones alto andinas (Leguía y Casas, 1999).

El parasitismo gastrointestinal es tratado en la actualidad mediante el control químico, que, dependiendo de la frecuencia y dosis empleada, los parásitos puedes generar resistencia a los antiparasitarios (Rojas, 2004). Asimismo, estos fármacos pueden dejar residuos en leche o carne que es destinada al consumo humano. Además, los problemas derivados del uso de fármacos pueden afectar la producción de alimentos orgánicos (Márquez, 2008). Estos inconvenientes merman la rentabilidad de la ganadería y, por lo tanto, afectan la calidad de vida de los ganaderos (Mendoza, 2000).

Los inconvenientes ocasionados por el control químico han replanteado el uso de los antiparasitarios, renovando el interés por la búsqueda de alternativas ecológicamente viables, sustentables y sin riesgos para la salud humana. Entre ellos se encuentra el control biológico, que consiste en utilizar organismos vivos con el objeto de controlar las poblaciones de otro organismo (Lecuona, 1995).

Existe una gama de poblaciones de organismos que han sido reportadas como antagonistas de nematodos, desde invertebrados hasta bacterias y hongos, siendo consideradas como posibles agentes potenciales de control de estos parásitos. Estos agentes han despertado un gran interés en la ciencia con la finalidad de buscar mecanismos viables que permitan realizar un control efectivo de los parásitos gastrointestinales en rumiantes (Herrera et al., 2004).

De los organismos reportados, la bacteria Bacillus thuringiensis ha sido desarrollada como un excelente agente biocontrolador de enfermedades causadas principalmente por insectos a cultivos de agrícolas de importancia (Lecuona, 1995). Para el caso de los nematodos, se reportan variedades de $B$. 
thuringiensis que tienen actividad letal frente a los estadios de vida libre, como son los huevos y las larvas de nematodos (López et al., 2002).

En el presente estudio realizado en Ayacucho, Perú, se evaluó la actividad nematicida in vitro del extracto proteico total de Bacillus thuringiensis frente a los estadios de vida libre de Nematodirus spathiger, huevos y larvas L3 infectivas.

\section{Materiales y Métodos}

\section{Lugar y Duración del Trabajo}

El presente trabajo se realizó en el Laboratorio de Parasitología de la Escuela de Formación Profesional de Medicina Veterinaria y en el Laboratorio de Biotecnología de la Escuela de Formación Profesional de Biología de la Universidad Nacional de San Cristóbal de Huamanga, Ayacucho, Perú. La zona se encuentra a una altitud de $2764 \mathrm{msnm}$ y el estudio se llevó a cabo entre enero y diciembre de 2011.

\section{Infección Experimental}

Se recolectaron cerca de $30 \mathrm{~g}$ de heces del recto de ovinos luego del sacrificio en el Centro de Beneficio de Quicapata. Las muestras fueron llevadas al laboratorio para diferenciar los huevos de Nematodirus spathiger (150-212 x 75-108 $\mu \mathrm{m})$ de otros huevos de tricostrongilos, utilizando cuadros de ayuda para la detección coprológica de huevos de los helmintos más comunes (Kassai, 2002). Los huevos fueron aislados mediante el uso de dos tamices, colocados uno debajo del otro. El superior con una criba de $200 \mu \mathrm{m}$ de abertura que permite retener y descartar las partículas grandes de las heces y el inferior con una criba de $53 \mu \mathrm{m}$ de abertura que permite retener los huevos de N. spathiger (Kassai, 2002). Los huevos fueron vertidos en un recipiente hasta sedimentar y eliminar el sobrenadante.
Si bien existe la posibilidad de quedar retenidos huevos de otras especies de nematodos, las larvas resultantes morirían luego del prolongado periodo de incubación a temperatura ambiente $\left(18{ }^{\circ} \mathrm{C}\right)$ y humedad variable, incluyendo periodos breves de desecación (Herrera et al., 2004).

El material sedimentado fue incubado por dos meses a temperatura ambiente $\left(18^{\circ} \mathrm{C}\right)$ hasta la obtención de larvas L3 infectivas de $N$. spathiger.

El cultivo fue colocado en el aparato de Baerman (Herrera et al., 2004) para liberar las larvas. Estas fueron administradas, vía oral, a un ovino joven (cinco meses de edad) desparasitado 20 días antes. Se empleó una dosis infectiva de 65 larvas L3. Posteriormente, en el día 28 posinfección se inició la recolección de muestras de heces para la obtención de los huevos y larvas L3 infectivas.

\section{Huevos de Nematodirus spathiger}

Las muestras de heces (400 g) colectadas del ovino infectado experimentalmente fueron almacenadas a $4{ }^{\circ} \mathrm{C}$ hasta su empleo. Las muestras fueron homogenizadas con agua destilada en un mortero y colocadas en recipientes de polietileno de $9 \mathrm{~L}$ de capacidad. La suspensión resultante fue filtrada a través de un tamiz, dejándose sedimentar por $10 \mathrm{~min}$, para luego eliminar el sobrenadante.

Al sedimento obtenido se le adicionó una solución saturada de azúcar (1280 g de azúcar rubia en $1000 \mathrm{ml}$ de agua destilada) en un recipiente de polietileno de forma cilíndrica de $1000 \mathrm{ml}$ de capacidad, en forma lenta y evitando la formación de burbujas. Se colocó una lámina de polietileno flexible en contacto con la suspensión durante $30 \mathrm{~min}$, permitiendo que los huevos del nematodo se dirijan hacia la superficie y se adhieran a lámina.

La lámina conteniendo los huevos se colocó en posición vertical en otro recipiente de polietileno y se lavó con agua destilada - 
para separar los huevos y dejarlos en la suspensión. Esta se almacenó hasta su empleo a $4{ }^{\circ} \mathrm{C}$ (adaptado de López et al., 2002 y Leguía y Casas, 1999). La modificación de la técnica consistió en el uso de una mayor cantidad de heces y, por lo tanto, en el uso de mayor volumen de las soluciones y recipientes de mayor capacidad.

\section{Larvas L3 de Nematodirus spathiger}

Muestras de heces $(400 \mathrm{~g})$ colectadas del ovino infectado experimentalmente fueron homogenizadas con agua en un mortero. Se dejó macerar hasta su fluidificación y se les depositó en recipientes de polietileno de $9 \mathrm{~L}$.

La suspensión se pasó a través de una malla, para retener las partículas grandes. Se dejó sedimentar eliminándose el sobrenadante, y el sedimento se transfirió a recipientes de polietileno con forma cuboide $(13 \mathrm{~cm}$ de largo, $10 \mathrm{~cm}$ de ancho y $6 \mathrm{~cm}$ de altura) para su incubación por dos meses a temperatura ambiente $\left(18^{\circ} \mathrm{C}\right)$ y humedad. El coprocultivo se dejó secar hasta la eliminación del exceso de humedad por $24 \mathrm{~h}$ y luego se procedió a realizar el método de Baerman, es decir la migración larvaria (Herrera et al., 2004), donde se colocó el material de cultivo envuelto en gasas de algodón y se sumergió en agua tibia, se dejó reposar por 24 h y se colectaron las larvas infectivas (adaptado de Leguía y Casas, 1999).

Extracto Proteico Total de B. thuringiensis

Se emplearon cinco variedades de $B$. thuringiensis del cepario del Laboratorio de Microbiología Ambiental y Biotecnología de la Universidad Nacional Mayor de San Marcos, Lima.

- kurstaki HD-1

- israeliensis WHO-2013-9

- israeliensis HD-500

- thompsoni HD-542

- neoleonensis T-24-001
Las variedades fueron reactivadas inoculando tres asadas del cultivo bacteriano en $100 \mathrm{ml}$ de caldo Luria Bertani (LB) e incubado por $72 \mathrm{~h}$ a $30^{\circ} \mathrm{C}$ en una incubadora de agitación orbital ( $80 \mathrm{rpm})$, hasta la formación de cristales y esporas en $72 \mathrm{~h}$.

Luego se sembró una asada a dos placas de Petri conteniendo Agar LB y se incubó por $24 \mathrm{~h}$ a $30^{\circ} \mathrm{C}$. Se inoculó a $200 \mathrm{ml}$ de caldo suplementado con leche peptonizada, incubándose por $72 \mathrm{~h}$ a $30^{\circ} \mathrm{C}$ en una incubadora de agitación orbital (130 rpm), hasta que se produzca la autolisis. Una vez autolizado el cultivo (1062 g), se centrifugó a $10500 \mathrm{~g}$, el sedimento bacteriano se lavó por tres veces con agua destilada y se resuspendió en solución de buffer fosfato (PBS) $0.01 \mathrm{M}, \mathrm{pH}$ 8.0 , obteniéndose $35 \mathrm{ml}$ de suspensión conteniendo esporas y cristales parasporales.

A fin de inhibir la actividad de las proteasas, se añadió $1 \mu \mathrm{l}$ de fluoruro de fenilmetilsulfonilo $(1 \mathrm{mM})$ por cada mililitro de la suspensión conteniendo esporas y cristales parasporales.

Las muestras fueron solubilizadas por adición de $1 \mu \mathrm{l}$ de 2-mercaptoetanol $(10 \mathrm{mM})$ por cada mililitro de la suspensión, con el objetivo de separar las cadenas polipeptídicas unidas por puentes disulfuro. Se incubaron a $37^{\circ} \mathrm{C}$ por $4 \mathrm{~h}$, luego las muestras $(10-500 \mathrm{~g})$ fueron centrifugadas a $10500 \mathrm{~g}$ durante 40 $\min$ a $4{ }^{\circ} \mathrm{C}$.

El sobrenadante conteniendo las proteínas fue procesado por el método de Biuret para determinar su concentración (adaptado de López et al., 2002). En la modificación de la técnica se sustituye el medio de cultivo SP por caldo suplementado con leche peptonizada para la obtención de esporas y cristales parasporales. Asimismo, en el análisis del contenido proteico, se sustituyó el método Bradford (electroforesis) (López et al., 2002) por el método Biuret cuantitativo. 


\section{Conteo de Nematodos}

El número total de huevos y larvas de $N$. spathiger se determinó mediante la observación al microscopio de un volumen de $1.2 \mathrm{ml}$ de la suspensión, tanto de huevos como de larvas (adaptado de López et al., 2002), siendo la modificación de la técnica el incremento del volumen de la suspensión a observar en el microscopio, de $5 \mu 1$ a $1.2 \mathrm{ml}$.

\section{Efecto Ovicida y Larvicida in vitro}

En una placa de Petri de $6 \mathrm{~cm}$ de diámetro se depositó $1.2 \mathrm{ml}$ de una suspensión que contiene huevos o larvas de $N$. spathiger y $1.2 \mathrm{ml}$ de la muestra de proteína purificada de $B$. thuringiensis. Se realizaron 10 repeticiones y adicionalmente 10 placas de Petri conteniendo solo huevos o larvas para el control. Las placas de Petri con los preparados se incubaron a 24,48 y $72 \mathrm{~h}$ a $25^{\circ} \mathrm{C}$. La observación se realizó bajo un microscopio usando el objetivo $4 X$, documentándose el número de huevos y larvas afectadas por las toxinas de $B$. thuringiensis.

Los huevos de $N$. spathiger del grupo control debían presentar un desarrollo embrionario normal, en tanto que los huevos expuestos al extracto proteico total de $B$. thuringiensis, en caso fueran afectados debían haber detenido el desarrollo embrionario. En forma similar, las larvas L3 infectivas del grupo control debían encontrarse en movimiento y aquellas expuestas al extracto proteico total debían estar inmóviles, casi en posición de línea recta o curva (López et al., 2002).

El porcentaje de mortalidad corregida (MC) de la toxina del B. thuringiensis se estimó usando la fórmula siguiente: $\mathrm{MC}=(\% \mathrm{~A}$ - \%B $) /(100-\% \mathrm{~B}) \times 100$, donde $\% \mathrm{~A}$ es la mortalidad de huevos y larvas frente al extracto proteico de cada una de las cinco variedades de $B$. thuringiensis empleadas, \%B es la mortalidad testigo registrado de huevos y larvas (Lecuona, 1995; Cundía, 2009).

\section{Análisis Estadístico}

Se empleó un diseño completamente randomizado con 5 tratamientos y 10 repeticiones (una placa de Petri por repetición) y un grupo control. Los datos se analizaron mediante un análisis de varianza y la comparación de promedios de actividad nematicida mediante la prueba de Tukey $(\mathrm{p}<0.05)$.

La relación funcional entre la concentración del extracto proteico total de $B$. thuringiensis y la actividad nematicida se evaluó mediante una regresión lineal.

\section{Resultados}

Como resultado de la incubación de los huevos y larvas L3 infectivas, en el grupo control se pudo observar un desarrollo embrionario normal en el interior de los huevos y movimiento de tipo ondulante y en espiral continuo en el caso de las larvas (Fig. 1a,b). En contraste, los huevos expuestos al extracto proteico total de $B$. thuringiensis detuvieron el desarrollo embrionario y las larvas estaban inmóviles en posición de línea recta o curva (Fig. 1c,d).

La actividad ovicida del extracto proteico total de $B$. thuringiensis se observa en el Cuadro 1. La variedad kurstaki HD-1 presentó la mayor actividad ovicida de las cinco variedades en estudio, obteniéndose 22.5, 29.0 y $44.7 \%$ de mortalidad corregida de huevos a las 24,48 y 72 h de exposición respectivamente; seguida de la variedad thompsoni HD-542 con 29.3\% a las 72 h de exposición. En contraste, se observa una baja actividad ovicida con las otras tres variedades.

El extracto proteico total de la variedad kurstaki HD-1 presentó la mayor actividad larvicida (Cuadro 2), obteniéndose 27.2, 41.9 y $45.6 \%$ de mortalidad corregida de larvas L3 infectivas a las 24,48 y $72 \mathrm{~h}$ de exposición respectivamente. La segunda actividad larvicida corresponde a thompsoni HD-542 
Cuadro 1. Porcentaje de mortalidad corregida de huevos de Nematodirus spathiger frente al extracto proteico total de cinco variedades de Bacillus thuringiensis

\begin{tabular}{lccc}
\hline Variedad & 24 horas & 48 horas & 72 horas \\
\hline kurstaki HD-1 & $22.5^{\mathrm{a}}$ & $29.0^{\mathrm{a}}$ & $44.7^{\mathrm{a}}$ \\
thompsoni HD-542 & $11.6^{\mathrm{b}}$ & $25.5^{\mathrm{b}}$ & $29.3^{\mathrm{b}}$ \\
neoleonensis T-24-001 & $5.3^{\mathrm{c}}$ & $12.4^{\mathrm{c}}$ & $19.6^{\mathrm{c}}$ \\
israeliensis HD-500 & $3.6^{\mathrm{d}}$ & $13.1^{\mathrm{c}}$ & $16.9^{\mathrm{d}}$ \\
israeliensis WHO-2013-9 & $4.3^{\mathrm{cd}}$ & $9.5^{\mathrm{d}}$ & $11.2^{\mathrm{e}}$ \\
Control & $0.0^{\mathrm{e}}$ & $0.0^{\mathrm{e}}$ & $0.0^{\mathrm{f}}$ \\
\hline
\end{tabular}

$a, b, c, d, e$ Superíndices diferentes dentro de columnas indica diferencia estadística $(p<0.05)$

Cuadro 2. Porcentaje de mortalidad corregida de larvas L3 infectivas de Nematodirus spathiger frente al extracto proteico total de cinco variedades de Bacillus thuringiensis

\begin{tabular}{lccc}
\hline Variedad & 24 horas & 48 horas & 72 horas \\
\hline kurstaki HD-1 & $27.2^{\mathrm{a}}$ & $41.9^{\mathrm{a}}$ & $45.6^{\mathrm{a}}$ \\
thompsoni HD-542 & $11.5^{\mathrm{b}}$ & $18.2^{\mathrm{b}}$ & $20.7^{\mathrm{b}}$ \\
israeliensis HD-500 & $1.9^{\mathrm{c}}$ & $11.0^{\mathrm{c}}$ & $11.9^{\mathrm{c}}$ \\
neoleonensis T-24-001 & $0.4^{\mathrm{cd}}$ & $3.3^{\mathrm{d}}$ & $6.4^{\mathrm{d}}$ \\
israeliensis WHO-2013-9 & $2.0^{\mathrm{c}}$ & $4.1^{\mathrm{d}}$ & $4.7^{\mathrm{de}}$ \\
Grupo control & $0.0^{\mathrm{d}}$ & $0.0^{\mathrm{d}}$ & $0.0^{\mathrm{e}}$ \\
\hline
\end{tabular}

$a, b, c, d, e$ Superíndices diferentes dentro de columnas indica diferencia estadística $(p<0.05)$

con $20.7 \%$ a las 72 h de exposición. Tal y como sucedió con la actividad ovicida, se observó una baja actividad larvicida con las variedades restantes de $B$. thuringiensis.

La concentración proteica del extracto proteico total de las cinco variedades de $B$. thuringiensis se muestra en el Cuadro 3. La variedad kurstaki HD-1 presentó la mayor concentración proteica $(5.042 \mathrm{mg} / \mathrm{ml})$, seguida de las variedades thompsoni HD-542, israelensis WHO-2013-9 y israelensis HD500. La variedad neoleonensis T-24-001 presentó la menor concentración $(2.256 \mathrm{mg} / \mathrm{ml})$.
En la Fig. 2 se observa el análisis de la relación funcional entre la concentración proteica del extracto proteico total de $B$. thuringiensis $(\mathrm{mg} / \mathrm{ml})$ y la actividad nematicida (ovicida y larvicida), mediante regresión lineal.

\section{Discusión}

El control biológico en el Perú está orientado al control de plagas agrícolas, siendo los entes rectores del mercado de control biológico el Servicio Nacional de Sanidad Agraria 


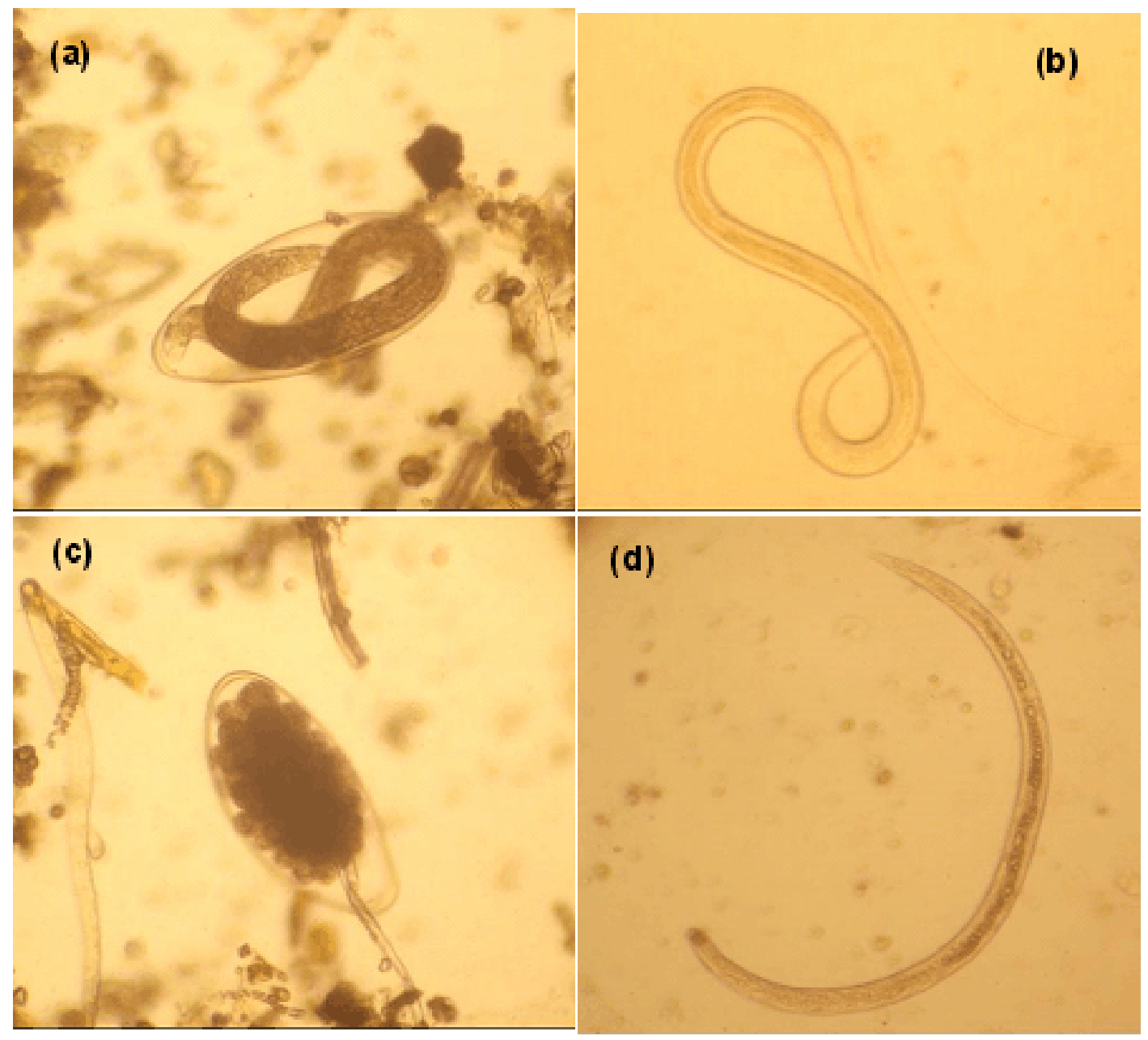

Figura 1. a) Huevo de Nematodirus spathiger en el grupo control con normal desarrollo embrionario a $72 \mathrm{~h}$ de incubación a $25^{\circ} \mathrm{C}$; b) Movimiento de tipo ondulante y en espiral continuo de la larva L3 infectiva de $N$. spathiger en el grupo control a $72 \mathrm{~h}$ de incubación a $25^{\circ} \mathrm{C}$; c) Huevo de N. spathiger muerto, resultado de la exposición al extracto proteico total de Bacillus thuringiensis; d) Larva L3 infectiva de N. spathiger muerta, resultado de la exposición al extracto proteico total de B. thuringiensis

Cuadro 3. Valores de absorvancia y concentración $(\mathrm{mg} / \mathrm{ml})$ obtenidos mediante la curva de calibración con ovoalbúmina

\begin{tabular}{lcc}
\hline $\begin{array}{l}\text { Sobrenadante conteniendo el } \\
\text { extracto proteico total }\end{array}$ & Absorvancia & $\begin{array}{c}\text { Concentración proteica } \\
(\mathrm{mg} / \mathrm{ml})\end{array}$ \\
\hline kurstaki HD-1 & 0.266 & 5.042 \\
thompsoni HD-542 & 0.168 & 3.172 \\
israeliensis HD-500 & 0.160 & 3.019 \\
israeliensis W HO-2013-9 & 0.163 & 3.076 \\
neoleonensis T-24-001 & 0.120 & 2.256 \\
\hline
\end{tabular}




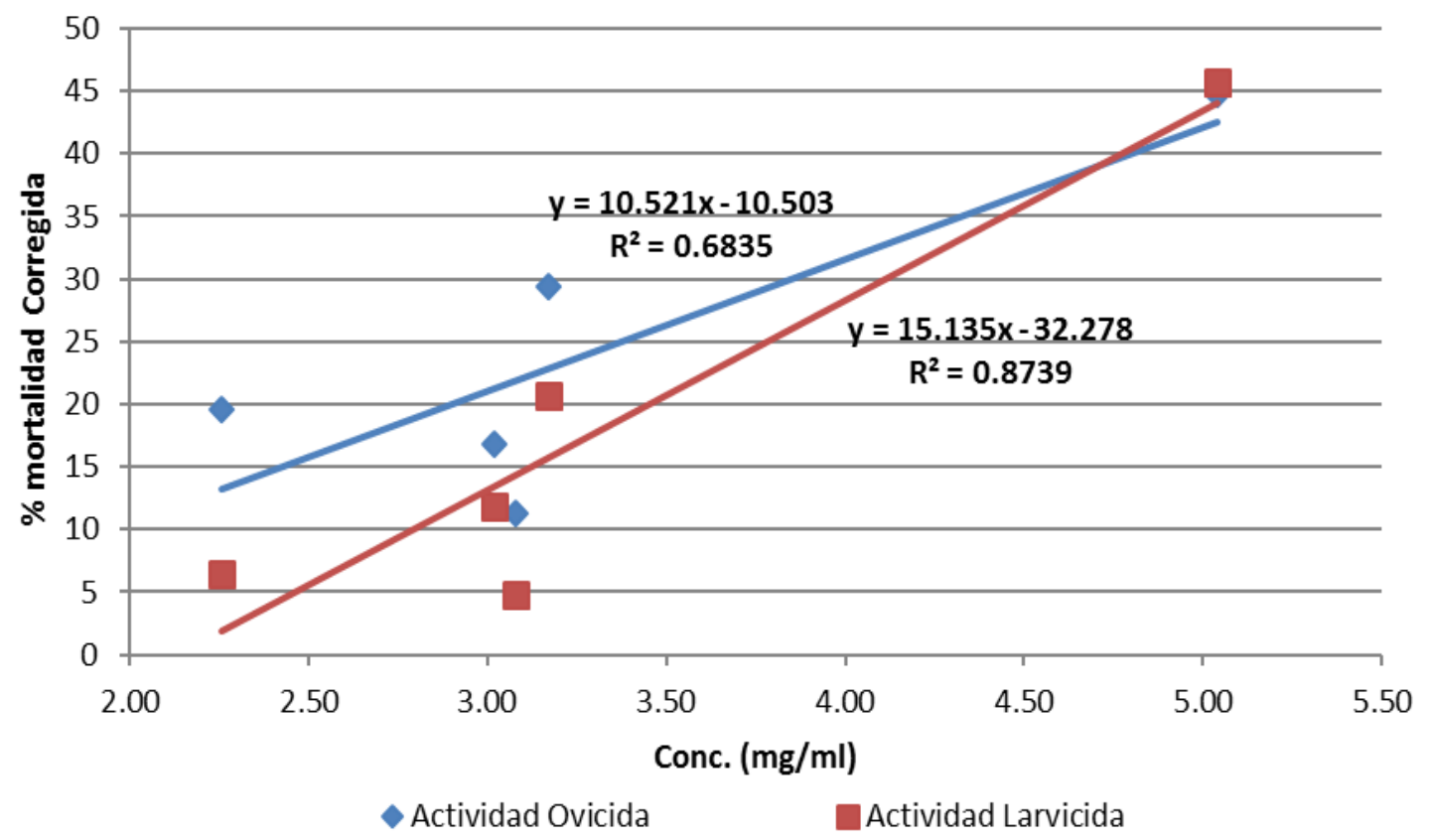

Figura 2. Comparación del porcentaje de mortalidad corregida de huevos y larvas L3 infectivas de Nematodirus spathiger a las $72 \mathrm{~h}$ frente a la concentración $(\mathrm{mg} / \mathrm{ml})$ del extracto proteico total de cinco variedades de Bacillus thuringiensis

(SENASA) y el Instituto Nacional de Innovación Agraria (INIA), mediante el Programa Nacional de Control Biológico, como lo señala Duarte (2012) en el análisis sobre el control biológico para apoyar las exportaciones agrícolas no tradicionales en Perú.

Son escasos los trabajos previamente reportados relacionados con $B$. thuringiensis. Prado (1995) registra el aislamiento de esta bacteria conjuntamente con Bacillus sphaericus en muestras de agua y suelo de las provincias de Huamanga y Huanta, Ayacucho, en tanto que Flores et al. (2010) mencionan ambas bacterias en trabajos de suelos agrícolas del Perú.

Los resultados del presente trabajo de investigación muestran un variado nivel de actividad nematicida in vitro del extracto proteico de las cinco variedades de $B$. thuringiensis frente a los huevos y larvas L3 infectivas de $N$. spathiger. Estos resulta- dos coinciden con los trabajos de Cundia (2009) y Flores et al. (2010) sobre Anopheles pseudopunctipennis y Culex sp, y de López et al. (2002) frente a huevos y larvas infectivas de Haemonchus contortus.

La actividad tóxica de $B$. thuringiensis está íntimamente relacionada con la presencia de las proteínas Cry; donde la actividad nematicida se relaciona con las proteínas Cry 5, Cry 6, Cry 12, Cry 13 y Cry 14 (Shin et al., 1995; Yadav, 2007). En este sentido Bt Kurstaki HD-1 presenta las proteínas Cry 5, 6 y 12, Bt Thompsoni HD-542 la proteína Cry 5, Bt Neoleonensis T-24-001 la proteína Cry 6 y Bt Israeliensis HD-500 y Bt Israeliensis WHO-2013-9 la proteína Cry 14.

El extracto proteico de $B$. thuringiensis contiene las toxinas solubilizadas activas, obtenidas mediante la adición de 2mercaptoetanol (10 mM). En forma natural y en el caso de insectos, la solubilización y 
activación de la proteína cristalina de la bacteria ocurre luego de la ingestión y paso por el tubo digestivo bajo condiciones alcalinas del intestino medio (Lecuona, 1995). En el caso de nematodos, el mecanismo de acción es relativamente similar; sin embargo, no existe cavidad bucal en el caso de huevos y larvas de tercer estadio, lo que sugiere que la actividad nematicida involucra la membrana cuticular de las larvas y la cubierta de los huevos, probablemente alterando la permeabilidad de estas membranas (López et al., 2002; Herrera et al., 2004).

La mayor actividad ovicida y larvicida correspondió a la variedad Kurstaki HD-1 con una mortalidad corregida de 44.7 y $45.6 \%$, respectivamente a las $72 \mathrm{~h}$ de exposición. Estos resultados se podrían comparar con el trabajo de López et al. (2002), cuyos resultados indican una mortalidad de $99 \%$ de huevos y de $90 \%$ de larvas infectivas de Haemonchus contortus a las 48 y $72 \mathrm{~h}$ de exposición, respectivamente, por efecto de toxinas de $B$. thuringiensis tripsinizadas y solubilizadas.

\section{Conclusiones}

- Se encontró efecto ovicida y larvicida contra Nematodirus spathiger en cinco variedades de Bacillus thuringiensis, a las 24,48 y 72 h de la exposición, siendo el mayor efecto ofrecido por Kurstaki HD-1.

- La actividad nematicida fue muy leve, siendo de $44.7 \%$ para la actividad ovicida y de $45.6 \%$ para la actividad larvicida a las 72 horas de la exposición, ofrecida por Kurstaki HD-1.

\section{Agradecimientos}

Los autores agradecen a la M.V.Z. Magaly Rodríguez Monje por su gran apoyo durante el manejo del nematodo gastroin- testinal en el Laboratorio de Parasitología Veterinaria de la UNSCH. Al Dr. Abad Flores Paucarima del Laboratorio de Microbiología Ambiental y Biotecnología de la UNMSM quien nos brindó ayuda y consejos desinteresados para la investigación. A la Blga. Mg. Martha Esther Valdivia Cuya, Decana de la Facultad de Ciencias Biológicas de la UNMSM, por su gran apoyo durante la obtención de reactivos para laboratorio.

\section{Literatura Citada}

1. Cundia O. 2009. Mortalidad producida por cepas Bacillus spp y Bacillus sphaericus 2362 en larvas de Anopheles pseudopunctipennis. Iguain, Huanta-Ayacucho 2250 msnm. Tesis de Biólogo. Ayacucho, Perú: Facultad de Ciencias Biológicas, UNSCH. $65 \mathrm{p}$.

2. Duarte F. 2012. El control biológico como estrategia para apoyar las exportaciones agrícolas no tradicionales en Perú: un análisis empírico. Contabilidad y Negocios 7(14): 81-100.

3. Flores A, Woolcott J, Egusquiza R, Patiño A, Huerta D, García F. 2010. Biodiversidad de Bacillus thuringiensis patotipos II y IV y Bacillus sphaericus aislados de suelos agrícolas peruanos. Biotiempo 10: 57-70.

4. Gómez L. 1984. Identificación de nematodos intestinales en ovinos criollos de acuerdo a la edad, sexo y época, beneficiados en el camal de Ayacucho 2800 msnm. Tesis de Biólogo. Ayacucho, Perú: Facultad de Ciencias Biológicas, UNSCH. 53 p.

5. Herrera D, Liébano $E$, López $M$, Mendoza P, Vázquez V. 2004. Diagnóstico y control de los nemátodos gastrointestinales de los rumiantes en México. Morelos, México: INIFAPCENID-PAVET. 173 p. 
6. Kassai T. 2002. Helmintología veterinaria. Zaragoza, España: Ed. Acribia. $258 \mathrm{p}$.

7. Lecuona R. 1995. Microorganismos patógenos empleados en el control microbiano de insectos plaga. Castelar, Argentina: IMYZA-CICA-INTA. 337 p.

8. Leguía G, Casas E. 1999. Enfermedades parasitarias y atlas parasitológico de camélidos sudamericanos. Lima, Perú: Ed de Mar. 190 p.

9. López Ma E, Flores J, Mendoza P, Bravo A, Herrera D, Liébano E, Vázquez VM, Vargas P. 2002. In vitro lethal activity of Bacillus Thuringiensis toxins against Haemonchus contortus eggs and infective larvae. Int $\mathbf{J}$ Nematology 12: 66-72.

10. Márquez D. 2008. Residuos químicos en alimentos de origen animal: problemas y desafíos para la inocuidad alimentaria en Colombia. Corpoica Cienc Tecnol Agropec 9(1): 124-135.

11. Mendoza P. 2000. Control alternativo de las helmintosis en rumiantes. Confe- rencia Electrónica. Red Latinoamericana de Helmintología. Argentina: INTA-FAO.

12. Prado M. 1995. Detección de Bacillus thuringiensis y Bacillus sphaericus en muestras de agua y suelo de las provincias de Huamanga y Huanta. Ayacucho. Tesis de Biólogo. Ayacucho, Perú: Facultad de Ciencias Biológicas, UNSCH. $56 \mathrm{p}$.

13. Rojas M. 2004. Nosoparasitosis de los rumiantes domésticos peruanos. $2^{\text {a }}$ ed. Lima: Martegraf. $154 \mathrm{p}$.

14. Shin S, Park H, Choi K, Koo T, Lee T, Kim I. 1995. Distribution of cry $V$-type insecticidal protein genes in Bacillus thuringiensis and cloning of cry $V$-type genes from Bacillus thuringiensis subsp. Kurstaki and Bacillus thuringiensis subsp. Entomocidus. Appl Environ Microbiol 61: 2402-2707.

15. Yadav B. 2007. Molecular characterization of cry / vip genes and efficacy of native Bacillus thuringiensis isolates. MSc Thesis. Dharwad, India: College of Agriculture, University of Agricultural Sciences. 129 p. 